\title{
PERSEPSI, SOSIAL EKONOMI, FAKTOR BUDAYA DENGA N PEMILIHAN PENOLONG PERSALINAN DI DESA LAMBUSANGO KABUPATEN BUTON
}

\author{
Taswin, Zaltia Amun \\ Fakultas Kesehatan Masyarakat Universitas Dayanu Ikhsanuddin
}

\begin{abstract}
Selection of birth attendants is a service form towards labor of a mother who is done by health workers such as doctor and midwife or a soothsayer. This study aimed to find out the correlation between perception, social-economy, culture and selection of birth attendants at lambusango chief in kapontori subdistrict, Buton regency. Research design was the analytic method with the crosssectional approach. Total sample was 67 respondents. The result of study was analyzed by using Chi square with $\mathrm{p}$ value $<0.05$. This study found that there was a correlation between perception and selection of birth attendants ( $\mathrm{p}$ value $=0.003<0.05$ ), there was a correlation between culture and selection of birth attendants $(\mathrm{p}$ value $=0.003<0,05)$ and there was no correlation between social economy and selection of birth attendants ( $\mathrm{p}$ value $=0.690>0.05$ ). The conclusion of study is perception and culture variable have a correlation with selection of the attendants while social economy has no correlation.
\end{abstract}

Keyword: perception, social economy, culture, birth attendants.

\section{PENDAHULUAN}

Cakupan persalinan oleh tenaga kesehatan di Indonesia pada Tahun 2013 sebesar 90,88\%. Berarti capaian ini telah memenuhi target Renstra pada tahun 2013 sebesar 89\%. Dari 33 Provinsi di Indonesia, hanya 12 Propinsi (36,37\%) yang belum mencapai target tersebut.

Persentasi persalinan yang ditolong oleh tenaga kesehatan di Provinsi Sulawesi Tenggara pada Tahun 2013 sebesar 93,28\% dan $6,72 \%$ penolong persalinan di tolong oleh dukun. Capaian tersebut lebih tinggi dari angka cakupan Nasional pada tahun yang sama, sekaligus juga telah memenuhi target Renstra tahun 2013 yang sebesar $89 \%$, namun demikian, masih terdapat 6 dari 12 Kabupaten/Kota di Provinsi Sulawesi Tenggara yang tidak dapat mencapai target tersebut pada tahun 2013 (Dinkes Kabupaten Buton, 2011).

Trend uraian penolong persalinan Kabupaten Buton pada tahun 2010-2012 berdasarkan data Susenas adalah sebagai berikut: Tahun 2010 penolong persalinan yang dilakukan oleh Dokter mencapai $5.28 \%$, Tahun 2011 mencapai 9.36 \% dan Tahun 2012 mencapai $5,4 \%$. Penolong persalinan yang dilakukan oleh Bidan pada Tahun 2010 mencapai $61.47 \%$ tahun 2012 mencapai 56.58\%dan tahun 2012 mencapai 59.41\%. Penolong persalinan yang dilakukan oleh Dukun pada tahun 2010 mencapai 31.73\%,
Tahun 2011 mencapai 33.52\%, dan Tahun 2012 mencapai $34.33 \%$. Angka harapan hidup (Tahun 2010 70.39, tahun 2011 70.69, dan tahun 2012 70.99).

Berdasarkan Hasil Survei Demografi dan Kesehatan Indonesia (SDKI), angka kematian ibu di Indonesia pada tahun 2012 mencapai 359/100.000 kelahiran, Angka ini masih jauh dari target tujuan pembangunan millenium (Millenium Development Goals/MDGs), yaitu 125/100.000 kelahiran pada tahun 2015.

\section{BAHAN DAN METODE Jenis Penelitian}

Penelitian ini menggunakan metode penelitian survei analitik, dengan desain penelitian cross sectional study.

\section{Lokasi Pelaksanaan}

Penelitian ini bertempat di desa Lambusango, Kecamatan Kapontori, Kabupaten Buton.

\section{Populasi dan Sampel \\ Populasi dalam penelitian ini adalah seluruh ibu menyusui pada tahun 2013 dan 2014 yang berdomisili di Desa Lambusango Kecamatan Kecamatan Kapontori Kabupaten Buton yaitu sebanyak 67 orang.}

\section{Teknik Pengumpulan Data}

Pengumpulan data menggunakan kuesioner yang berisi daftar pertanyaan yang berhubungan 
dengan variabel yang diteliti, dokumentasi yaitu sejumlah data-data atau informasi dari Puskesmas. SPSS adalah alat yang digunakan untuk mengolah data-data yang diperoleh serta yang digunakan dalam penyusunan laporan penelitian.

\section{Pengolahan dan Penyajian Data}

Analisis univariat dilakukan pada masing-masing variabel untuk mengetahui karakteristik masing-masing variabel. Variabel ditampilkan dalam bentuk tabel distribusi faktor-faktor yang berhubungan dengan Pemilihan Penolong Persalinan.

Analisis Chi-Square digunakan untuk analisis bivariat guna mengetahui hubungan dua variabel, yaitu variabel bebas dan variabel terikat. Untuk membuktikan ada atau tidaknya hubungan antara Persepsi, Tingkat Sosial Ekonomi Keluarga, Faktor Budaya dengan Pemilihan Penolong Persalinan. Uji statistik yang digunakan adalah Chi Square dengan derajat kepercayaan $95 \%$ bila $p<0,05$ menunjukkan hubungan bermakna, bila $p>0,05$ menunjukkan hubungan tidak bermakna.

\section{HASIL PENELITIAN \\ Analisis Variabel Penelitian}

Variabel-variabel yang diteliti adalah variabel dependen meliputi Pemilihan Penolong Persalinan dan variabel independen meliputi Persepsi, Tingkat Sosial Ekonomi Keluarga, dan Faktor Budaya. Hasil analisis univariat dan bivariat terhadap variabel-variabel yang diteliti tersebut adalah sebagai berikut:

Tabel 1. Distribusi Jawaban Responden tentang Persepsi, Sosial Ekonomi, Faktor Budaya dengan Pemilihan Penolong Persalinan di Desa Lambusango Kabupaten Buton

\begin{tabular}{ccccccc}
\hline \multirow{2}{*}{ Variabel } & \multicolumn{2}{c}{ Persepsi } & \multicolumn{3}{c}{ Faktor Budaya/ Kebiasaan } \\
& Positif & Negatif & Total & Berpengaruh & $\begin{array}{c}\text { Tidak } \\
\text { Berpengaruh }\end{array}$ & Total \\
\hline $\mathbf{N}$ & 24 & 43 & 67 & 52 & 15 & 67 \\
$\%$ & $35,8 \%$ & $64,2 \%$ & $100 \%$ & $77,6 \%$ & $22,4 \%$ & $100 \%$ \\
\hline \multirow{2}{*}{ Variabel } & \multicolumn{3}{c}{ Sosial Ekonomi } & Pemilihan Penolong Persalinan \\
& Cukup & Kurang & Total & Bidan & Dukun Bayi & Total \\
\hline N & 31 & 36 & 67 & 20 & 47 & 67 \\
\% & $46,3 \%$ & $53,7 \%$ & $100 \%$ & $29,9 \%$ & $70,1 \%$ & $100 \%$ \\
\hline
\end{tabular}

Berdasarkan Tabel 1 menunjukkan bahwa dari 67 responden menurut persepsi responden bahwa sebagian besar responden memiliki persepsi negatif yaitu sebanyak 43 orang $(64,2 \%)$, sedangkan responden yang memiliki persepsi positif yaitu sebanyak 24 orang $(35,8 \%)$. Dari 67 responden menurut tingkat pendapatan adalah responden yang memiliki pendapatan cukup yaitu sebanyak 31 orang $(46,3 \%)$, sedangkan responden yang memiliki pendapatan kurang yaitu sebanyak 36 orang $(53,7 \%)$ menunjukkan bahwa dari 67 responden menurut faktor budaya yaitu responden yang berpengaruh terhadap faktor budaya sebanyak 52 orang $(77,6 \%)$ sedangkan yang tidak berpengaruh terhadap faktor budaya adalah sebanyak 15 orang $(22,4 \%)$.

Berdasarkan Tabel tersebut menunjukkan bahwa dari 67 responden menurut
Pemilihan Penolong Persalinan menunjukkan bahwa sebagian besar responden bersalin di bantu oleh dukun bayi yaitu sebanyak47 orang $(70,1 \%)$ sedangkan responden yang Bersalin di bantu oleh bidan sebanyak 20 orang $(20,9 \%)$.

Berdasarkan hasil pengujian statistik Chi square menunjukan bahwa nilai pvalue $=$ $0,003<0,05$. maka dapat disimpulkan bahwa Ho ditolak, artinya ada hubungan bermakna antara persepsi dengan pemilihan penolong persalinan. Dan hasil pengujian statistik Chi square menunjukan bahwa nilai pvalue $=0,690>0,05$. maka dapat disimpulkan bahwa Ho diterima, artinya tidak ada hubungan bermakna antara sosial ekonomi dengan pemilihan penolongan persalinan. Berdasarkan hasil pengujian statistik Chi square menunjukan bahwa nilai pvalue $=$ $0,000<0,05$ maka dapat disimpulkan bahwa Ho ditolak, artinya ada hubungan bermakna 
antara faktor budaya dengan pemilihan penolongan persalinan.

Tabel 2. Hubungan Variabel Penelitian dengan Pemilihan Penolong Persalinan di Desa Lambusango Kecamatan Kapontori Kabupaten Buton

\begin{tabular}{|c|c|c|c|c|c|c|c|}
\hline \multirow{3}{*}{ Variabel Penelitian } & \multicolumn{4}{|c|}{$\begin{array}{c}\text { Pemilihan Penolong } \\
\text { Persalinan }\end{array}$} & \multirow{2}{*}{\multicolumn{2}{|c|}{ Jumlah }} & \multirow{3}{*}{ Uji Statistik } \\
\hline & \multicolumn{2}{|c|}{ Bidan } & \multicolumn{2}{|c|}{ Dukun Bayi } & & & \\
\hline & $\mathbf{n}$ & $\%$ & $\mathbf{n}$ & $\%$ & $\mathbf{n}$ & $\%$ & \\
\hline \multicolumn{8}{|l|}{ Persepsi } \\
\hline Negatif & 7 & 10,4 & 36 & 53,7 & 43 & 64,2 & \multirow{3}{*}{$\mathrm{P}$ value $=0,0003$} \\
\hline Positif & 13 & 19,4 & 11 & 16,4 & 24 & 35,8 & \\
\hline Total & 20 & 29,9 & 47 & 70,1 & 67 & 100 & \\
\hline \multicolumn{8}{|l|}{ Sosial Ekonomi } \\
\hline Cukup & 10 & 14,9 & 21 & 31,3 & 31 & 46,3 & \multirow{3}{*}{$P$ value $=0,690$} \\
\hline Kurang & 10 & 14,9 & 26 & 38,8 & 36 & 53,7 & \\
\hline Total & 20 & 29,9 & 47 & 70,1 & 67 & 100 & \\
\hline \multicolumn{8}{|l|}{ Faktor Budaya } \\
\hline Berpengaruh & 7 & 10,4 & 45 & 67,2 & 52 & 77,6 & \multirow{3}{*}{$\mathrm{P}$ value $=0,0000$} \\
\hline Tidak berpengaruh & 13 & 19,4 & 2 & 3 & 15 & 22,4 & \\
\hline Total & 20 & 29,9 & 47 & 70,1 & 67 & 100 & \\
\hline
\end{tabular}

\section{PEMBAHASAN}

Dari hasil penelitian yang dilakukan di Desa Lambusango, diperoleh data jumlah ibu yang menyusui pada tahun 2013 dan 2014 sebanyak 67 orang, dengan 20 orang bersalin dibantu oleh tenaga kesehatan dan 47 orang bersalin dibantu oleh dukun bayi. Masyarakat sendiri memiliki persepsi dan sikap yang berbeda-beda terhadap tenaga kesehatan dan dukun bayi. Banyak hal yang perlu diketahui dalam pembentukan persepsi dan sikap tersebut. Persepsi positif masyarakat terhadap penolong persalinan dengan dukun bayi sebesar $16,4 \%$ dan persepsi negatif masyarakat terhadap penolong persalinan dengan bidan sebesar $10.4 \%$. Hal ini sesuai dengan teori bahwa persepsi masyarakat terhadap tenaga kesehatan baik, namun apabila dilihat dari angka persepsi terhadap dukun bayi, angka tersebut menunjukkan bahwa masyarakat masih memandang bahwa melakukan persalinan di dukun bayi mempunyai manfaat terhadap keselamatan ibu dan bayi. Sikap masyarakat terhadap penolong persalinan dapat diketahui bahwa sikap positif masyarakat terhadap penolong persalinan dengan dukun bayi sebesar $19,4 \%$ dan sikap negatif masyarakat terhadap dukun bayi sebesar $53,7 \%$. Dalam penentuan sikap yang utuh, pengetahuan, berpikir, keyakinan dan emosi memegang peranan penting. Sikap mudah terbentuk jika melibatkan faktor emosional. Hal ini sudah cukup baik, namun apabila melihat pada persentase sikap negatif, masih banyak ibu memilih dukun bayi sebagai penolong persalinan dan kebanyakan ibu beranggapan bahwa memilih dukun bayi sebagai penolong persalinan adalah hal yang sudah biasa dan mereka sudah mempercayakan kepada dukun bayi sebagai penolong persalinannya. Maka hal tersebut masih perlu menjadi perhatian sampai masyarakat mampu merubah pola pikirnya terhadap pemilihan pertolongan persalinan yang aman.

Berdasarkan tingkat pendapatan responden di Desa Lambusango diketahui bahwa ibu yang tingkat pendapatan cukup sebanyak 31 responden dan ibu yang pendapatan kurang sebanyak 36 responden. Hal ini menginditifikasikan bahwa keluarga dengan pendapatan yang rendah akan beralih untuk memanfaatkan dukun bayi dalam pertolongan persalinan, hal ini dikarenakan biaya atau tarif yang dikenakan oleh dukun bayi cenderung jauh lebih murah dibandingkan dengan tarif oleh bidan atau tenaga medis lain, artinya ibu bersalin dengan pendapatan keluarga rendah kemungkinan memilih dukun bayi dibandingkan ibu dengan berpendapatan tinggi akan cenderung memilih bidan/tenaga kesehatan lainnya.

Dalam penelitian di Desa Lambusango dikatakan bahwa faktor budaya sangat 
berpengaruh terhadap pemilihan penolong persalinan terhadap dukun bayi, Karena masyarakat di Lambusango Induk masih berpegang teguh pada budaya dalam hal persalinan. Mereka lebih memilih dukun bayi sebagai penolong persalinan, dengan alasan bahwa melakukan persalinan terhadap dukun bayi merupakan hal turun temurun dan sudah menjadi kebiasaan di desa Lambusango Induk tersebut.

Hal ini sejalan dengan penelitian yang di lakukan oleh Linda (2004) mengemukakan bahwa pada dasarnya peran kebudayaan terhadap kesehatan masyarakat adalah untuk membentuk, mengatur dan mempengaruhi tindakan dan kegiatan-kegiatan individu suatu kelompok sosial untuk memenuhi berbagai kebutuhan kesehatan. Memang tidak semua praktek prilaku masyarakat yang pada awalnya betujuan untuk menjaga kesehatan dirinya adalah merupakan praktek yang sesuai dengan ketentuan medis atau kesehatan, apalagi jika persepsi tentang kesehatan ataupun penyebab terjadinya sakit sudah berbeda sekali dengan konsep medis, tentunya upaya mengatasinya juga berbeda di sesuaikan dengan keyakinan ataupun kepercayaan-kepercayaan yang sudah di anut secara turun temurun. Sehingga lebih banyak menimbulkan dampak-dampak yang merugikan bagi kesehatan.

\section{KESIMPULAN DAN SARAN}

Pada analisis bivariat menunjukan adanya hubungan yang bermakna antara persepsi dan faktor budaya dengan Pemilihan Penolong Persalinan, sedangkan untuk sosial ekonomi tidak memiliki hubungan. Pada kenyataannya ini perlu peran tenaga kesehatan untuk selalu tak henti-hentinya melakukan sosialisasi terhadap masyarakat, dengan tujuan untuk menekankan kepada masyarakat utamanya ibu-ibu untuk melakukan persalinan terhadap tenaga kesehatan, mengingat untuk mengurangi Angka Kematian Ibu dan Anak.

Disarankan kepada petugas Puskesmas Kapontori Kabupaten Buton bahwa perlu pendekatan budaya dan adat istiadat terhadap masyarakat setempat, dalam penempatan bidan, peningkatan pelayanan kesehatan, dan perlu dilakukan pembinaan serta pelatihan terhadap dukun bayi, mengingat untuk mengurangi angka kematian ibu dan anak di Indonesia, utamanya di desa Lambusango, Kecamatan Kapontori, Kabupaten Buton.

DAFTAR PUSTAKA

Arikunto, Suharsimi. (2008). Prosedur Penelitian Suatu Pendekatan Praktek Edisi Revisi V. Jakarta: Rineka Cipta.http://iyosrosmana.wordpress.com/ 2009/06/19/populasi-dan-sampel/Diakses tanggal 30 Mei 2013.

Dinas Kesehatan Kabupaten Buton, Profil Kesehatan Kabupaten Buton Tahun 2011.

Djaali. (2008). Pengertian Skala Guttman. http://nenibest.blogspot. com/. Diakses tanggal 17 November 2013.

Imron, Moch. (2010). Metodologi Penelitian Bidang Kesehatan. Sagung Seto: Jakarta.

Kusmiyati, Yuni. (2009). Perawatan ibu Hamil (Asuhan Ibu Hamil). Yogyakarta: Fitramaya.

Notoadmodjo. (2005). Metode Penelitian Kesehatan, Edisi Revisi. Rineka Cipta: Jakarta.

Sugiarto. (2011). Metode penelitian. http://kelas armansyah. wordpress. com/metodepenelitian-populasi-sampling-dan-teknikacak. Diakses tanggal 20 November 2013. 